\title{
MEDICAL CARE AND ITS DELIVERY: AN ECONOMIC APPRAISAL*
}

\author{
Judith R. LAve aNd Lester B. Lave $\dagger$
}

\section{GouRMand ANd Food-A Fable}

The people of Gourmand loved good food. They ate in good restaurants, donated money for cooking research, and instructed their government to safeguard all matters having to do with food. Long ago, the food industry had been in total chaos. There were many restaurants, some very small. Anyone could call himself a chef or open a restaurant. In choosing a restaurant, one could never be sure that the meal would be good. A commission of distinguished chefs studied the situation and recommended that no one be allowed to touch food except for qualified chefs. "Food is too important to be left to amateurs," they said. Qualified chefs were licensed by the state with severe penalties for anyone else who engaged in cooking. Certain exceptions were made for food preparation in the home, but a person could serve only his own family. Furthermore, to become a qualified chef, a man had to complete at least twenty-one years of training (including four years of college, four years of cooking school, and one year of apprenticeship). All cooking schools had to be first class.

These reforms did succeed in raising the quality of cooking. But a restaurant meal became substantially more expensive. A second commission observed that not everyone could afford to eat out. "No one," they said, "should be denied a good meal because of his income." Furthermore, they argued that chefs should work toward the goal of giving everyone "complete physical and psychological satisfaction." For those people who could not afford to eat out, the government declared that they should be allowed to do so as often as they liked and the government would pay. For others, it was recommended that they organize themselves in groups and pay part of their income into a pool that would undertake to pay the costs incurred by members in dining out. To insure the greatest satisfaction, the groups were set up so that a member could eat out anywhere and as often as he liked, could have as elaborate a meal as he desired, and would have to pay nothing or only a small percentage of the cost. The cost of joining such prepaid dining clubs rose sharply.

Long ago, most restaurants would have one chef to prepare the food. A few restaurants were more elaborate, with chefs specializing in roasting, fish, salads, sauces, and many other things. People rarely went to these elaborate restaurants

* This investigation was supported by the PHS Grant 3 ROI HS 00069 HSR from the National Center for Health Services Research and Development. We thank Thomas Morton and Lester Silverman for helpful suggestions.

tRespectively, Lecturer and Associate Professor of Economics, Graduate School of Industrial Administration, Carnegie-Mellon University. 
since they were so expensive. With the establishment of prepaid dining clubs, everyone wanted to eat at these fancy restaurants. At the same time, young chefs in school disdained going to cook in a small restaurant where they would have to cook everything. The pay was higher and it was much more prestigious to specialize and cook at a really fancy restaurant. Soon there were not enough chefs to keep the small restaurants open.

With prepaid clubs and free meals for the poor, many people started eating their three-course meals at the elaborate restaurants. Then they began to increase the number of courses, directing the chef to "serve the best with no thought for the bill." (Recently a 3r7-course meal was served.)

The costs of eating out rose faster and faster. A new government commission reported as follows: (I) Noting that licensed chefs were being used to peel potatoes and wash lettuce, the commission recommended that these tasks be handed over to licensed dishwashers (whose three years of dishwashing training included cooking courses) or to some new category of personnel. (2) Concluding that many licensed chefs were overworked, the commission recommended that cooking schools be expanded, that the length of training be shortened, and that applicants with lesser qualifications be admitted. (3) The commission also observed that chefs were unhappy because people seemed to be more concerned about the decor and service than about the food. (In a recent taste test, not only could one patron not tell the difference between $a 1930$ and a 1970 vintage but he also could not distinguish between white and red wines. He explained that he always ordered the r930 vintage because he knew that only a really good restaurant would stock such an expensive wine.)

The commission agreed that weighty problems faced the nation. They recommended that a national prepayment group be established which everyone must join. They recommended that chefs continue to be paid on the basis of the number of dishes they prepared. They recommended that every Gourmandese be given the right to eat anywhere he chose and as elaborately as he chose and pay nothing.

These recommendations were adopted. Large numbers of people spent all of their time ordering incredibly elaborate meals. Kitchens became marvels of new, expensive equipment. All those who were not consuming restaurant food were in the kitchen preparing it. Since no one in Gourmand did anything except prepare or eat meals, the country collapsed.

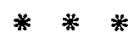

I

INTRODUCTION

There is a pervasive feeling of imminent crisis with respect to the delivery of medical services in the United States. Expenditures on medical care are rising without any offsetting decline in our mortality rates-which compare poorly with 
those of many other countries. ${ }^{1}$ The costs of medical care are increasing at an accelerating rate. ${ }^{2}$ Many big-city hospitals, which service the poor, are in a state of financial distress. ${ }^{3}$ Medicare and Medicaid, the programs developed to enable the disadvantaged to obtain medical care, set off the current price spiral by creating a rapid increase in the demand for medical services while the supply of those services could be increased only slowly. The middle class now finds it difficult to obtain the kind of medical care it has come to expect, namely that of an interested, warm physician who is familiar with the family history. There is a perceived over-all shortage of nurses and physicians. Moreover, many concerned individuals believe that the existing physicians are not distributed well. They argue that there are relatively too few primary physicians and too many specialists, too few physicians in the inner cities and in rural areas, and too many in the affluent suburbs.

As a response to these and many other problems, government involvement in the delivery of medical services has increased. The share of personal expenditures on medical services financed by public funds rose from twenty-two per cent in fiscal Ig66 to thirty-six per cent in fiscal Ig69. 4 These funds have been expended on demonstration projects to experiment with alternative ways of delivering medical care and on innovative training programs, as well as on more traditional services. The trend is clear, and few people believe that government participation will decrease in the future.

The purpose of this paper is to discuss some aspects of the structure of the medical care industry, with special emphasis on some of the interrelationships that we believe are important and should be considered in formulating policy. Since medical services are desired not for their own sake but because they are an important input into the acquisition of health, we begin with a discussion of the nature of this relationship.

II

\section{The Relationship Between Medical Care Expenditures and Health}

Medical services are but one of the many inputs contributing to improved health. Health, itself an amorphous concept, has been defined by the World Health Organization as "a state of complete physical, mental and social well-being and not merely the absence of disease or infirmity." The relationship between medical care expenditures and "complete physical, mental and social well-being" is weak, and, even

\footnotetext{
${ }^{1}$ In 1968 , for the average life expectancy of males, the United States ranked 2Ist among all countries; for females, it ranked roth.

2 Total personal expenditures on health care rose from $\$ 36.4$ billion in 1966 to $\$ 52.6$ billion in 1969 . Medical care prices rose at an average annual rate of 2.6 per cent from 1960 to 1966 and at an average annual rate of 6.4 per cent since then.

${ }^{3}$ See Kotulak, 14 Hospitals Might Move into Suburbs, Chicago Tribune, Apr. 26, x970, at $x$.

"Cooper, Medical Care Outlays for Aged and Nonaged Persons, I966-rg6g, Soc. Szc. Bull., July I970, at 3,9 .

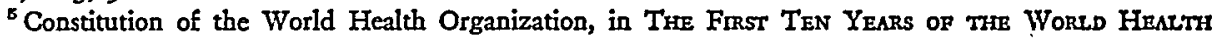
Organization 459 (r958).
} 
when we move from the very abstract concept of health to more conventional ones, the association between medical care expenditures and health remains tenuous. Few of the occasions when medical care is sought are matters of life and death. Some medical care expenditures are necessary to sustain life, to deter incapacitation, or to rehabilitate members of society, but, as the majority of illnesses are self-limiting, most medical services provide support, reassurance, and palliation without affecting the length of the illness. Some medical expenditures, such as nose restructuring, facial uplifts, and bosom expansions, are purely luxury expenditures of the rich or vain.

Since one's basic state of health is affected partly by one's socioeconomic status and physical environment, it may be more efficient to attack the cause of bad health rather than the symptom of it. Let us elaborate further.

Many "diseases" are more prevalent among the poor; the poor experience more days of complete or partial disability. ${ }^{6}$ The low-income morbidity is caused not only by a relatively low use of medical services but by the poverty itself. Poverty is usually accompanied by bad nutrition, substandard housing, and inadequate sanitation. The interrelationships are complicated: poverty contributes to poor health, poor health to poverty. Peter de Vise has presented a grim picture of the health status of the residents of the Chicago ghetto. ${ }^{7}$ One could well argue that what he describes is a prime symptom of poverty; while better medical care may temporarily alleviate the symptoms, the root causes will remain. ${ }^{8}$ This argument has been succinctly put by Geiger: "To treat symptoms, and then to send the patients back, unchanged in knowledge, attitude or behavior to the same physical and social environment-also unchanged-that overwhelmingly helped to produce that illness and will do so again is to provide antibiotics for cholera and then send the patients back to drink again from the Broad Street pump." For poorer families, we would contend that resources devoted to the alleviation of poverty and health education would have greater impact on improving family health than would resources devoted to medical services. ${ }^{10}$

'See Lerner, Social Differences in Physical Health, in Poverty and Health 69 (J. Kosa, A. Antonovsky \& I. Zola eds. I969).

"P. de Vise et al., Slum Medicine: Chicago's Apartheid Health System (ig69).

${ }^{8}$ We are basically arguing that the popular model frequently advanced to explain the continuously observed relationship between poverty and ill health-"the cycle of poverty"-is inherently self-defeating. The model is diagrammed like this:

Poverty $\longrightarrow$ ill health $\longrightarrow$ low productivity $\longrightarrow$ poverty

Direct linkages imply that intercession at any point in the chain will have the same effect and will break the cycle, but this is naive. While in some few instances one might be able to break into the cycle by providing medical services that will finally eliminate ill health and break the cycle, in general it will not be that easy.

${ }^{3} \mathrm{H}$. Geiger, "Poor and Professional, Who Takes the Handle of the Broad Street Pump?," paper presented at the 94th annual meeting of the American Public Health Ass'n, San Francisco, Nov. I, Ig66.

${ }^{10}$ One of the principal advantages of the OEO neighborhood health centers is alleged to be their ability to intervene in a range of processes affecting health rather than simply providing medical care. People working at the centers will supposedly spend much time educating people, changing their assumptions as to when care should be sought, providing information about nutrition, and so forth. 
An individual's general health status depends not only on his socioeconomic status but also on his life style and environment. His drinking, sleeping, eating, and exercising habits all influence his health, as does the environment in which he works and lives. ${ }^{11}$ It has been shown that air pollution leads to increases in the incidence of bronchitis, lung cancer, other respiratory diseases, and many other diseases. ${ }^{12}$ A recent study concluded that a fifty per cent abatement in the level of air pollution would lower the economic cost of morbidity and mortality almost as much as finding an immediate and complete cure for cancer. ${ }^{13}$ For middle class families in large cities, air pollution is probably the single most important factor adversely affecting family health. Relatively small expenditures on abating pollution would do more to improve the general health of the family than much larger expenditures on medical care that the family currently undertakes. We must shift our attention from medical care as an end in itself to medical care as only one of many inputs into improved health.

III

\section{The Amorphous Concept of Quality}

Since higher medical costs are often attributed to higher quality medical care, we must discuss the quality problem. We consider two dimensions of quality: (I) the subjective perception of the patient of the care he is receiving, and (2) objective medical efficacy (accuracy of the diagnosis and effectiveness of the treatment). These two dimensions are not totally separable since the patient's perception of his treatment is likely to affect both his response to and his acquiescence in the treatment program.

The Gourmandese found that the setting and service of their dinner was of primary importance. As long as the cost is zero, the customer will demand more attendants and a more attractive setting; if it costs no more, why not get the best? The Gourmandese also found that they wanted their sauces prepared by specialists, rather than general cooks, since it cost no more. After all, the better the training of the chef, the more likely that the product is better, even if one is not capable of tasting the difference. The better the training of the chef, the more prestige accrues to the customer who is knowledgeable enough to choose him.

As with the Gourmandese, the patient often focuses on the setting in which he receives care. This is certainly true with institutionalized care. But, as is true with restaurants, better service, higher quality foods, and more pleasant surroundings usually cost more to provide. Perhaps more important, few patients know enough about medicine to have any way of judging a physician other than by his credentials, his attitude toward them, and the warmth and respect offered by those working

\footnotetext{
${ }^{11}$ See, e.g., Ferris, Epidemiological Studies on Air Pollution and Health, 16 Arch. Environ. Health 541 (1968).

${ }^{12}$ L. Lave \& Seskin, Air Pollution and Human Health, I69 Scrence 723 (1970).

${ }^{18}$ L. Lave, Air Pollution Damage, in Research on Environmentai Qunlity (A. Kneese ed. 197I).
} 
with him. There is little reason to believe that the patient's perception of the quality of the medical care he received would correlate highly with the judgment of other physicians who might serve as consultants. ${ }^{14}$

There are two aspects of the objective measure of quality that we wish to discuss: first, the costs associated with reducing the probability of error or mishap (defined as a deviation from the desired outcome) and, second, the impossibility of giving everybody the "best possible medicine."

Nothing is sure in medicine. There is some small probability that a child will go into shock and die when administered a routine injection. No one can undergo even minor surgery with complete assurance that he will live through the operation, much less that the operation will be a success. Everyone would agree that reducing the probabilities of error or mishap would enhance quality, but one unfortunate property that medicine shares with almost all other human activity is that it is increasingly costly to continue to lower such risks. For example, in perhaps one appendectomy in a thousand a situation will arise where a gastrointestinal surgeon could do a better job than a general surgeon. On the other hand, it is both costly and time consuming to give general surgeons the extra training required to become gastrointestinal surgeons. Is it worthwhile to spend such extra time and money so that all appendectomies can be done by gastrointestinal surgeons or so that all broken bones can be set by orthopedic surgeons? If the reader's answer to these questions is affirmative, we could cite even more extreme instances where minute increases in quality are achieved only at astronomical costs.

A second and much misconceived aspect of quality is reflected in the ubiquitous assertion that every American is entitled to the best medicine. Just as there are only a few really superb chefs but a large number of good ones, there are only a few really superb physicians but many who are quite competent. It is conceptually impossible for everyone to be served by the few top physicians, and some people will always be served by the few worst physicians.

The contradiction is not quite so obvious when we think about the scope of treatment rather than the skill of the physician. For example, the American Academy of Pediatrics has published a set of standards which delineate what is deemed adequate care for a child under the age of eighteen. ${ }^{15}$ These standards specify the number and timing of physical examinations and innoculations. Without regard to the geographical maldistribution of pediatricians, one study estimates that if only the recommended care were provided, all pediatricians could treat only one-third of the children in the United States. ${ }^{16}$ This would mean "good" medical care for one-third of the children; no medical care for the rest.

\footnotetext{
${ }^{26}$ Peterson, Medical Care in the U.S., Scientific AMERICAN, Aug. 1963, at I9, 21.

26 Council on Pediatric Practice, American Academy of Pediatrics, Standards of Child Heatth CARE (1967).

10 Yankauer, Connelly \& Feldman, Pediatric Practice in the United States, 45 Pedratrics 52r, 525 (1970).
} 
The response to this analysis has been twofold. The first is to study which of the pediatricians' tasks could be performed as well by people with much less training. The basic conclusion of these studies is that about eighty per cent of the average pediatrician's practice could be done by people who have much less training. ${ }^{17}$ The second is to ask whether all the items recommended by the American Academy of Pediatrics are really efficacious. Why should a newborn be seen eight to twelve times during his first year of life? Why should he have four complete physical examinations? Could not four to six visits be arranged so that the child received just as good medical care? (Note that the validity of immunization is not at issue.)

At the end of this paper we will return to the issue of quality in discussing whether we really want "the best possible medical care for everyone," even if it could be produced. We now turn to describing some aspects of the medical care service industry itself. In particular we focus on the following issues: (a) factors affecting the individual's decision to seek medical care, $(b)$ the extent of substitution that can be obtained in treating a patient, $(c)$ the concept of the paramedic, $(d)$ the mode of delivering medical care, and $(e)$ the interrelationships between financing and costs.

\section{The Demand for Medical Services}

The demand for medical care originates with the individual. His decision to seek care-which usually begins with a visit to a physician-will depend in part on the following interrelated factors: (r) his underlying state of health, (2) his perception of when he needs medical care, and (3) the cost to him of obtaining care. We have already discussed the first factor. The perception of when medical care is needed has changed a great deal over time. At one point, medical care was sought only if an individual could no longer function adequately, and even then only if it appeared that the problem would not correct itself. Much of the demand for medical care of course still revolves around acute remedial situations, such as accidents or severe illnesses. One quite different perception of the need for medical care that has emerged involves the seeking of "preventive maintenance" in the form of routine physical examinations or, more currently, "multiphasic health screening." Finally, some people seek medical care whenever they are not in a "state of complete physical, mental and social well-being." The perception of when medical care should be sought depends on the age, sex, marital status, income, and education of a person. ${ }^{18}$

\footnotetext{
${ }^{17}$ See, e.g., H. Silver, "New Pattern of Personnel for Children's Services: A Blueprint for Child Health Care for the Next Decade," paper presented at the 38 th annual meeting of the American College of Pediatrics, Chicago, Oct. 18 , I969.

${ }^{18}$ See, e.g., The Demand for Medical Care, in I Report of THE Commisston on the Cost of Medical Care 57 (1964).
} 
The cost to a person of obtaining care seldom has much connection with the price charged by the physician or hospital. In many cases, care is costless because of medical insurance or group-practice prepayment. In other cases, the cost of a simple visit may be extraordinarily high because of the difficulty and expense of giving up work and traveling to the physician. While the evidence on relationships is not as conclusive as one might desire, cost to the consumer is an important factor influencing the demand for care. ${ }^{10}$ When the cost of a visit is zero, as under group-practice prepayment plans, people demand more visits than when they must pay for each visit. When hospitalization is free because of comprehensive insurance coverage, people are apt to be hospitalized more than when they must pay the full costs themselves. ${ }^{20}$

Once the decision has been made to seek care, the consumer cedes his decisionmaking power to the physician. It is the physician who determines the inputs of goods and services and what risks to take. As Arrow has pointed out, the consumer has the dual characteristics of being ignorant about medicine and loathing to take risks concerning his health. ${ }^{21}$ Thus, he is likely to ask the physician to make all the decisions and to instruct him to spare no expense. This arrangement is an unusual one in our economy, unusual even for the circumstances. Few people would think of giving their auto repairman or plumber the same instructions, in spite of their ignorance and concern.

\section{V}

\section{The Technology}

In treating a given illness, the various medical inputs-the nurse, the aide, the physician, the surgeon, the drugs, and the hospital bed-can be combined in different ways. In fact, it is an important economic insight that there are many ways of delivering medical care. A routine physical examination, for example, can be performed solely by a physician, or by a nurse-physician combination where the medical history, weight, height, and temperature are taken by the nurse, or by a nurse-technician-physician combination where technicians perform a vast number of tests and the role of the physician is limited to the interpretation of the tests (as in multiphasic screening). These different ways of delivering the same service can be designed to provide medical care of a similar quality but with vastly different implications for cost and utilization of scarce resources, such as physician time. These substitutions are not only limited to routine care or to ambulatory care. At one time, many of the tasks (such as the drawing of blood and the giving of intravenous injections or anesthesia) which are now handled competently by paramedics and allied health manpower could be legally performed only by physicians. ${ }^{22}$

\footnotetext{
${ }^{20}$ This evidence is summarized in Lave \& Kaplan, Incentives in Health Insurance, r970 (working paper, Graduate School of Industrial Administration, Carnegie-Mellon University).

${ }^{20}$ See note 33 infra and accompanying text.

${ }^{21}$ Arrow, Uncertainty and the Welfare Economics of Medical Care, 53 AM. Econ. Rev. 94I (1963).

${ }^{22} \mathrm{~J}$. Weiss, The Changing Job Structure of Health Manpower, I966 (unpublished dissertation, Harvard University).
} 
There are many limitations on the extent to which these possible substitutions are actually used. The physician, who usually manages the case, has been trained to give "the best possible care" and may not consider alternatives. Quality may be defined (by the patient especially) in terms of the inputs rather than the outcome. The method used to finance care may distort the cost relationships so that the cheapest treatment program for the patient is not the cheapest to society. Professional prerogatives may set arbitrary limits on who can do what. Fear of malpractice suits leads doctors to conformity in their actions and inhibits anything that might be construed as corner-cutting. ${ }^{23}$ Legal limitations on some substitutions are set. These legal limitations are always advocated as ways to protect the patient from bad quality medical care, but they often work to serve the self-interest of professional groups and to raise costs. Consider, for example, the fact that most states prohibit nurse-midwives from delivering babies. While these laws might once have protected women from untrained amateurs, an $\mathrm{RN}$ with special training in obstetrics can handle a normal delivery and can recognize more complicated cases which warrant the obstetrician's special skill. It takes twelve years to train an obstetrician and four years to train a nurse-midwife. The cost differences are much greater than three to one since medical school and residency are more expensive per year than nursing school. Nor is this a new, untried idea dreamed by wellmeaning but ignorant economists. In European countries, where the infant and maternal mortality rates are low (the contrast with the United States is embarrassing), most obstetrical care is provided by the midwife.

The current interest in developing paramedics (personnel being trained to assume some of the tasks usually performed by the physician) may be interpreted as an attempt to increase the substitution possibilities in the production of health. Task analyses have indicated that physicians perform many tasks which could easily be delegated to paramedics, ${ }^{24}$ and there have been a number of demonstration projects in which nurses with some additional training have adequately performed tasks usually undertaken by the physician. ${ }^{25}$ There have been a number of training programs-some of which give nurses additional training, others of which train new personnel-in which individuals are specifically trained to supplant the physician in the performance of certain tasks. The full implications of these programs will be unknown for some time. Analyses of existing programs indicate that paramedics can perform their tasks well and that the paramedics are generally well accepted by the patient. ${ }^{26}$ General physician acceptance is unclear, but physicians who have

\footnotetext{
${ }^{23}$ Bailey, Economies of Scale in Medical Practice, in Empirical Studies in Health Economics 255 (H. Klarman ed. 1970).

${ }^{24}$ See Yankauer, Connelly \& Feldman, supra note 16.

${ }^{25}$ See, e.g., Lewis \& Resnik, The Nurse Clinic-Dynamics of Ambulatory Care-New Roles for Old Disciplines, J. Kan. MEd. Soc'x, Mar. I967, at 123-24.

${ }^{26}$ It should be noted, however, that in one study of patient acceptance, patients at the lower and upper ends of the income scale "accepted" the paramedic at a low level compared to those with middle income levels. The poor felt they were getting lower quality care because they were poor, and the rich
} 
worked with them report satisfaction. Acceptance by other health professionals, who may feel threatened, has been slow. Legal issues having to do with licensure have not been solved. Long-run effects on the redistribution of income within the health services industry are unknown. ${ }^{27}$

\section{Physician Choice of Practice Setting}

The institutional settings in which medical care is delivered probably have some effect on costs. A physician may decide to practice by himself, in partnership with a small number of colleagues (such as a group of obstetricians or pediatricians), or in a larger institutional setting, such as a clinic or formal group practice. Some years ago, group practice, especially prepaid group practice, was heralded as the solution to many cost (and quality) problems. Investigators liked what they saw in the Kaiser groups and attempted to persuade physicians to replicate this situation and to encourage the government to promote group practice. More recently, questions have been raised as to whether group practice itself really does result in a more efficient utilization of physicians and facilities. ${ }^{28}$ One may wonder whether the original investigators were guilty of trying to generalize from the experience of a prepaid group that had considerable constraints on its access to hospital beds. ${ }^{29}$

As economists we would predict that physicians would decide to locate their practice in a place which they find both pleasant and challenging. Certainly one aspect of the locational decision will be the amount of service they can render, but other aspects will include the income earned, number of hours worked, associations with colleagues, and the availability of amenities of life. It is not hard to understand why physicians are becoming more concentrated in urban business areas and in the suburbs, leaving rural areas and inner city ghettos with little or no medical care.

We make the above observations because they imply that many current policies will be ineffective. Increasing the number of physicians is unlikely to increase the number who settle in rural areas. It would probably take a massive increase in the supply before physicians would give up the amenities of urban or suburban life for the higher incomes associated with rural practice. (This judgment may be incorrect if the social awareness of current medical students is as strong as reported.) Directly increasing the income of rural physicians is also not likely to have much of an effect in attracting physicians. There are currently rural communities that offer

felt cheated because they were paying for the best. See L. Pondy et al., A Study of Patient Acceptance of the Physician's Assistant, I970 (unpublished manuscript, Duke University).

${ }^{a 7}$ For a detailed discussion about the paramedics, see J. Lave, L. Lave \& T. Morton, A Survey of the Literature on Paramedics, 1970 (working paper, Graduate School of Industrial Administration, Carnegie-Mellon University).

${ }^{28}$ Bailey, stpra note 23.

${ }^{20}$ See Klarman, Approaches to Moderating the Increases in Medical Care Costs, 7 Med. CARE I75, 180-81 (1969). 
higher incomes than many urban physicians are earning but are still unable to secure physicians. Indeed, the policy of increasing the supply of physicians may have some bad implications for resource allocation, as suggested by Ginzsberg. ${ }^{30}$

Should the government intervene directly and tell physicians where to practice? The cost of such a policy in a democratic society would be great. Instead, we should design mechanisms to encourage physicians to practice in rural areas for a part of their career. For example, the military draft for physicians could be used to supply physicians to rural areas for two or three years. Probably a better mechanism would involve offering to pay tuition, or some part of the expenses, of medical students in return for two or three years of practice in specified areas (as does Canada's province of Newfoundland). Other suggestions to improve medical services in these areas include the development of paramedics. If paramedics could be made available to work with rural physicians or to function in field stations without a physician present, some of the unattractive features of rural practice, such as excessively long hours, might diminish, perhaps increasing the flow of physicians to rural areas.

\section{VII}

The Relationship Between Financing Methods and the

Cost of Medical Care

If the resources needed to treat a particular medical case were fixed in proportion, if the prices of medical inputs never changed (the supply of inputs being perfectly elastic), and if the price of medical care never affected how much was demanded, then there is no way that the method of financing medical care and of reimbursing the providers of medical care could affect costs. In fact, however, an individual's decision to seek medical care often depends on its price to him, medical inputs can be combined in many different ways, and prices often reflect the patient's ability to pay. ${ }^{31}$ Consequently we believe that the methods of financing and reimbursement are a crucial element. Let us explore these relationships in four aspects.

(I) Impact of more spending. Increasing expenditures on medical services do not necessarily give rise to proportionately more of such services. This statement has been supported by our experience in the period immediately following the implementation of Medicare and Medicaid. The effect of increasing purchasing power of some consumers was to redistribute existing resources-perhaps in a socially more optimal way, to draw some more medical services into the industry, and to cause an increase in prices. Cooper has estimated that, of the total dollar increase in expenditures for health services since I966, approximately fifty per cent can be attributed to price increases alone. ${ }^{82}$

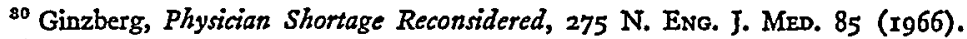

${ }^{3}$ See Kessel, Price Discrimination in Medicine, I J. LAw \& Econ. 20 (1958). See also Pauly, Efficiency Incentives and Reimbursement for Health Care, INQURY, Mar. I970, at II4.

${ }^{a s}$ Cooper, supra note 4 , at II.
} 
(2) Distortions created by insurance coverage. Medical insurance which covers the costs of some medical inputs and not of others will probably influence the treatment pattern of a specific disease as the patient, or the doctor acting in his interest, attempts to minimize the patient's expense; this process may result in higher overall costs. Thus, it is common for insurance to cover the costs of certain diagnostic tests only if they are performed while the insured is in a hospital; a patient might therefore be hospitalized, say, for two days at a cost of $\$ 200$, of which he pays nothing, in order to avoid his having to pay $\$ 40$ for these tests as an outpatient. This kind of selective insurance provides built-in incentives to substitute more expensive inputs for the cheaper inputs with no improvement in the quality of care. While evidence of the existence or extent of misallocative effects from these perverse incentives is not strong, ${ }^{33}$ in the short run, any increase in the demand for inputs which are in relatively fixed supply could be expected to contribute to an increase in their prices; in the long run, pressure would develop for expanding the more expensive resource. $^{34}$ The consequence of the tendencies adverted to in the foregoing example would be that hospitals would be enlarged so that most testing could be done on an inpatient basis to accommodate those with insurance.

(3) Physician self-interest in decision making. The way in which a physician is reimbursed may affect his decision on how to manage a particular case. While we have no desire to impugn any individual physician or his selected treatment pattern, we do argue that decisions will be colored by personal gain. When the patient presents himself to the physician, the physician chooses the course of treatment and the various inputs that will be used. One of these inputs is his own skill and time. Models of physician behavior are incomplete, but Mosma has suggested that, since the physician also has a financial interest in the treatment of the patient, the patient's interest may not be the only factor affecting the physician's advice. ${ }^{35} \mathrm{He}$ argues that one of the factors influencing a physician's behavior may be the marginal revenue to him for performing the services. The ethical problem may seem less substantial to the physician where a third-party insurer or the government, rather than the patient, is paying the bill.

Mosma develops a number of hypotheses which stem from the above argument. He tests them by examining physician behavior under fee-for-service practice and in salary settings. He focuses primarily on the extent of surgery, since it is here that major effects should occur. His results show clearly that the rates of surgery are much higher for groups in which the individuals are treated by physicians under

\footnotetext{
${ }^{33}$ See Lewis \& Keairnes, Controlling Costs of Medical Care by Expanding Insurance Coverage, 282 N. ENG. J. MED. I405 (1970), for a description of one test of this relationship. Extension of Blue Cross benefits to ambulatory care was not accompanied by a significant reduction in the test group's hospitalization costs.

ot See Pauly, $A$ Measure of the Welfare Cost of Health Insutance, 4 Health Services Research 28x (I969).

${ }^{35}$ Mosma, Marginal Revenue and the Demand for Physicians' Services, in ExrPIricar Stodies in HEALTH EcONOMICs, supra note 23, at $\mathbf{4 5}$.
} 
fee-for-service than those treated by salaried physicians. The prime effect shows up in those procedures the efficacy of which is often subject to some doubt, such as tonsillectomies, appendectomies, and hysterectomies. He concludes that the differences in rates of recourse to surgery seem to represent overutilization in the fee-for-service situation rather than underutilization in the salaried group situation.

Proponents of salaried group medical practice also believe that a fee for service may create incentives for physicians to recommend additional visits. There has been no good empirical work undertaken to test this hypothesis. The argument does, however, suggest that alternative ways of financing medical care should be encouraged.

(4) Inefficiences encouraged by cost reimbursement. The costs of hospital care are likely to be affected by the method of reimbursement. Economic models of the interaction between the methods chosen to reimburse hospitals and hospital costs have not been fully developed and tested. There is some consensus that hospital costs are rising rapidly since most reimbursement is done on the basis of cost. ${ }^{30}$ Concern about this possibility has prompted legislative proposals looking toward "prospective reimbursement" and more sophisticated cost limitations under Medicare. ${ }^{37}$

\section{VIII}

\section{How Much Medical Care?}

The last question we would like to raise is this: How much medical care do we really want? Stated otherwise, what level of medical intervention with the disease process is socially optimal?

The question is generated by the many miracles of modern medicine, by the unbelievable techniques that can postpone death for a short period of time, by transplant techniques and the technology of artificial organs, and by the entire genre of medical care exemplified by that given President Eisenhower in the last year of his life. Decisions about the amount of care to be rendered in a particular case are often made by physicians; but, since costs are being increasingly borne by society, the question must be regarded as one of public policy. If an individual completely finances his own medical care, the decision is of course solely his, and he should not be denied what he is able and willing to pay for. But if the individual's care is being financed either through groups (by means of insurance or a prepaid group plan) or by the government, then the decision is no longer an individual one.

Group insurance is much less expensive than individual contracts. This means that the individual is not motivated to learn the range of choices of contract possible and the costs of adding various kinds of coverage. Thus, group contracts

\footnotetext{
${ }^{36}$ See Klarman, supra note 29 , at $185-87$.

${ }^{37}$ See the proposed Social Security Amendments of 1970, H.R. I7550, 91st Cong., 2d Sess. (passed by the House, May 2I, 1970); H.R. Rep. No. 9I-I096, 9Ist Cong., 2d Sess. 29-39 (r970).
} 
seem to have a way of providing greater and greater coverage over time. But it is not true that all would agree greater coverage is a good thing. For example, psychiatric care (unlimited visits to a psychiatrist's office), renal dialysis, and organ transplants may be benefits most people want to have available, but, given the potential cost of such treatments and the small probability of success of some of them, many people would prefer to take their chances with reduced coverage and lower premiums.

There are really two aspects of the problem. The first aspect concerns the allocation of resources within the medical care industry itself. The crucial nature of the problem is brought out by John Knowles: $:^{38}$

When I was recently ["]the visit["] on the medical service, the first five patients presented to me all happened, by a curious coincidence, to have the same problem. And it serves to point up the incongruity of what we're doing here. All five were elderly, chronic alcoholics with massive GI bleeding and end-stage liver disease. All five were in coma and we were treating them vigorously, with everything medicine has to offer. They had intravenous lines, and central venous pressure catheters, and tracheostomies, and positive pressure respirators, and suction and Seng stocking tubes, and all the rest. They had house staff and students and nurses working on them around the clock. They had consultants of every shape and sort. They were running up bills of five hundred dollars a day, week after week. . . . Certainly I think they should be treated, just as I think that a large hospital like this is the place where this brand of complex medicine ought to be carried out. But you can't help reflecting, as you look at all this stainless steel and tubing and sophisticated equipment, that right outside your door there are people with TB who aren't getting antibiotics, and kids who aren't getting vaccinations, and women who aren't getting prenatal care.

As economists, we would point out that the truest measure of the social cost of treating the five patients described is not just the dollars spent in providing the care. Rather it is the value of the best alternative use-Dr. Knowles suggests some poignant possibilities-to which those health dollars might have been put. Evaluated in terms of such "opportunity costs," the social losses from the misallocation of medical resources might be staggering indeed.

The second aspect of the resource allocation problem is of course how much of society's total resources we really want to allocate to providing medical care. How can we choose? If we all had the best possible medical care and could avail ourselves of the most modern medical technology, we could easily devote one-third of our resources to medical services, without feeling very much healthier! At present, there are recreational facilities to be enjoyed, books to be read, houses to be built, good food to be eaten, and children to be educated. Do we really want to go the way of the Gourmandese?

\footnotetext{
${ }^{38}$ Quoted in M. Crichton, Five Pattents: The Hospital Explained 200 (i970).
} 


\section{Summary aNd Conclusion}

There is a growing crisis in the delivery of medical care. We have argued that some economic insights could have been used to foresee the current crisis and to identify which proposed solutions would prove helpful and which would not. We have stressed that medical care is only one way of improving health and aired our suspicion that in I970-America we are probably spending too much on medical care and too little on other means of achieving better health. We have noted that there are many possibilities for substituting inputs in the production of medical care and that much of the current crisis could be relieved if some of the artificial traditional, institutional, and legal barriers were removed so that patients could get needed (and only needed) treatment at the least cost. Immediate progress could be expected from changes in the direction of economic incentives and expansion of the utilization of paramedical personnel.

As a nation, we have been pumping many extra dollars into the medical care sector without realizing that the sector had little capability of giving additional service. Either we must relax some demands on the sector or engage in policies to expand the production of services radically. But up to now we have concentrated unwisely on removing those incentives needed to discourage the patient from seeking the best possible care, when something less would serve about as well, and from demanding other amenities without regard to the cost.

Much of the over-all problem seems to us to stem from illusions about the value of medical care that tend seriously to distort the outcomes of political processes in dealing with health issues. Regrettably, we have not analyzed here what we believe good quality to be in medicine, but we have said enough to reveal our doubt that more care is always necessarily better from a social standpoint or that quality questions can be divorced from cost. It is time for illusions on these points to be reexamined, for expectations to be modified, and for policy makers to attempt to solve some of the real problems. As a nation, we have come to expect too much from medicine and to regard physicians, or at least their services, as the best chance for earthly salvation. Unfortunately, medicine is not going to secure for us, at any price, "a state of complete physical, mental and social well-being." 